\title{
VERIFICAÇÃO DO USO DO BIM NOS ESCRITÓRIOS DA REGIÃO METROPOLITANA DO CRAJUBAR CEARENSE
}

\author{
Ana Verônica Gonçalves Borges - ana.borges@ufca.edu.br \\ Universidade Federal do Cariri \\ Juazeiro do Norte - Ceará
}

\author{
Allan Pereira Gomes da Silva - allannuke@gmail.com \\ Universidade Federal do Cariri \\ Juazeiro do Norte - Ceará
}

Igor Antonio Alves Pereira - igorantonio321@hotmail.com

Universidade Federal do Cariri

Juazeiro do Norte - Ceará

José Igor Noronha Sousa - joseigornoronha@gmail.com

Universidade Federal do Cariri

Juazeiro do Norte - Ceará

Mateus Florêncio Sousa-mateus.florencio@aluno.ufca.br

Universidade Federal do Cariri

Juazeiro do Norte - Ceará

Pedro Henrique Castro do Nascimento - henrikelpn@gmail.com

Universidade Federal do Cariri

Juazeiro do Norte - Ceará

\section{Resumo}

A construção civil é uma das áreas que mais crescem e, dessa forma, mais demandam tecnologias para seu desenvolvimento, em vários aspectos, como econômico e sustentável. Apesar da significativa melhoria nos modelos e processos de construção a partir do século XXI com a criação de softwares para computadores, ainda assim, muitos erros de compatibilização eram, e são, cometidos. Assim, visando melhorar esses processos, tornando a construção mais rápida, diminuindo erros, prejuízos e agressão ao meio ambiente, surgiu a metodologia Building Information Modeling (BIM). Esse novo jeito de construir vem ganhando bastante espaço nos últimos anos e sendo mais solicitado. Visto isso, este estudo tem como objetivo avaliar quais escritórios particulares de engenharia e arquitetura na região de CRAJUBAR estão adotando a metodologia BIM em seus projetos e quais melhorias foram obtidas durante todo o fluxo de trabalho da construção, além de observar quanto ao emprego da metodologia para a construção de edificações sustentáveis.

Palavras-chave: BIM, Fluxo de trabalho, sustentabilidade. 


\title{
VERIFICATION OF THE USE OF THE BIM IN OFFICES IN THE METROPOLITAN REGION OF CRAJUBAR CEARENSE
}

\begin{abstract}
:
Civil Construction is one of the fastest growing areas and, therefore, it demands more technologies for its development, in several aspects, such as economic and sustainable ones. Despite the great improvement in the building models and processes since the 21 st century with the creation of software for computers, still, many compatibility errors were, and are, made. Thus, with the aim of improving these processes, making construction faster and reducing errors, losses and damage to the environment, the Building Information Modeling (BIM) methodology was emerged. This new way of building has gotten a lot of space in recent years and being more requested. In view of this, this study aims to assess which private engineering and architecture offices in the CRAJUBAR region (Cariri - Ceará State, in Brazil) are adopting the BIM methodology in their projects and which improvements they have been added throughout the building workflow, and addition, to check the use of the methodology in the construction of sustainable buildings.
\end{abstract}

Keywords: Civil Construction, BIM, Workflow, Sustainability.

\section{INTRODUÇÃO}

Com o passar do tempo, a área da construção civil foi passando por diversas inovações tecnológicas, como novos softwares, novas técnicas e novas filosofias de trabalho, tudo isso para melhorar a qualidade do serviço e facilitar o processo de criação e execução dos projetos. Uma das inovações mais promissoras do ramo da engenharia é o BIM ou Building Information Modeling (Modelagem da Informação da Construção), que é uma filosofia de construção que se insere em cada etapa do processo construtivo de uma edificação, desde os primeiros esboços da construção até a sua demolição.

Com o BIM, é possível produzir um modelo 3D do projeto rico em informações e detalhes, planejar todo o passo a passo do projeto com cronogramas bem montados, calcular todos os custos do projeto, explorar as opções mais sustentáveis para a edificação e até mesmo acompanhar todo o ciclo de vida da construção. De acordo com Eastman et al. (2014), os proprietários estão cada vez mais demandando o BIM e alterando os termos contratuais para viabilizar seu uso, além de que novos papéis estão sendo desenvolvidos dentro do ramo por causa da existência dessa nova tecnologia. Isso mostra o impacto que o BIM está fazendo no mercado da construção civil, sendo assim necessário que os profissionais da área saibam utilizar as ferramentas que o BIM proporciona e que as empresas comecem a se adaptar a essa nova filosofia que irá dominar o mercado futuramente.

Visando a sustentabilidade, o BIM adiciona essa a sua sexta dimensão (6D) o conceito de edificações sustentáveis. Ramos (2016) diz que, o modelo BIM ajuda o processo de análise sustentável para uma certificação "verde" da edificação facilitando o estudo solar, a análise energética, o consumo de água, entre outros.

No Brasil, a partir do ano de 2021, de acordo com o Decreto Presidencial $N^{\circ} 10.306$, assinado em 02 de abril de 2020, será obrigatório o uso do BIM no desenvolvimento de projetos de engenharia e arquitetura para obras públicas. Levando em consideração que o Decreto Presidencial é mais voltado para as obras públicas, o presente estudo visa verificar como está 
sendo feita a implantação do BIM em escritórios particulares de engenharia e arquitetura, se eles estão aderindo ou não, analisar em que nível esses se encontram na utilização do BIM oferece, a utilização das ferramentas que auxiliam na sustentabilidade e como funcionou a transição nessas empresas da antiga metodologia que eles utilizavam para a metodologia BIM. O campo de estudo da pesquisa é a Região CRAJUBAR, que consiste na Região Metropolitana do Cariri Cearense, que são as cidades de Crato, Juazeiro do Norte e Barbalha.

\section{REFERENCIAL TEÓRICO}

O surgimento da metodologia BIM no cenário da construção civil trouxe consigo a divisão de dimensões que trabalham as diferentes fases de projeto e execução de uma construção. De acordo com o INBEC Brasil (Instituto de Educação Continuada), o BIM não é só uma tecnologia que gera modelos em $3 \mathrm{D}$, mas uma tecnologia que trabalha em várias dimensões, as quais são classificadas da seguinte forma:

- 3D - Dimensões Tradicionais (Modelagem)

- 4D - Planejamento

- 5D - Orçamento

- 6D - Sustentabilidade

- 7D - Gestão de Instalações

- 8D - Segurança do Trabalho

Parte destas dimensões pode ser trabalhada paralelamente, sem a necessidade de seguir um fluxo de trabalho linear, mas um fluxo colaborativo entre as diferentes fases de projeto e de execução, aprimorando os dados associados a um modelo para compartilhar um maior nível de entendimento do empreendimento.

Segundo Eastman et al. (2014), o uso do BIM proporciona benefícios em diferentes fases da obra, desde a pré-construção para o proprietário tratando-se dos estudos de viabilidade até o pós-construção através do gerenciamento de informações do modelo virtual. Dentre as principais vantagens da utilização desta metodologia estão:

- Aumento da qualidade e do desempenho da construção;

- Visualização antecipada e mais precisa de um projeto;

- Geração de desenhos 2D precisos e consistentes em qualquer etapa do projeto;

- Colaboração antecipada entre múltiplas disciplinas de projeto;

- Extração de estimativas de custo durante a etapa de projeto;

- Incremento da eficiência energética e sustentabilidade;

- Descoberta de erros de projeto e omissões antes da construção (detecção de interferências);

- Melhor gerenciamento das edificações.

\section{METODOLOGIA}

Para desenvolver o seguinte estudo, foi realizado um levantamento nos escritórios de engenharia particulares da região. Para Gil (2008), esse tipo de pesquisa procede-se à solicitação de dados sobre o assunto estudado para um grupo considerável de indivíduos, para logo depois, por meio de uma análise quantitativa, alcançar conclusões condizentes com os dados apurados. Um questionário foi produzido com perguntas relacionadas ao BIM e à sua implementação. Uma parte das perguntas foi formulada visando as dimensões do BIM (3D e 6D), com o intuito de saber como os escritórios particulares utilizam o BIM e o quanto eles realmente conseguem 
extrair dos vários benefícios que essa metodologia traz. O formulário foi enviado via internet para uma amostra de 21 empresas particulares da área da construção civil na Região CRAJUBAR, que abrange as cidades de Juazeiro do Norte, Barbalha e Crato, municípios localizados no sul do Ceará.

O questionário possui duas etapas. Na primeira etapa, os escritórios responderiam a seguinte pergunta: "O seu escritório utiliza a metodologia BIM?", podendo a respostas ser "sim" ou "não". Na segunda etapa, dependendo da resposta, o entrevistado é direcionado para diferentes perguntas relacionadas ao uso, ou não, da metodologia BIM, em que os escritórios que adotavam essa metodologia responderiam a seis perguntas, e os escritórios que não a adotavam, responderiam a três perguntas diferentes.

No caso de a empresa utilizar o BIM, as perguntas seguem a ordem mostrada na tabela a seguir:

Tabela 1 - Questionário às empresas que utilizam a metodologia BIM

\begin{tabular}{|c|c|}
\hline PERGUNTAS & ALTERNATIVA \\
\hline $\begin{array}{l}\text { 1) Como funcionou a transição da antiga } \\
\text { metodologia (CAD, 2D) para a } \\
\text { metodologia BIM? }\end{array}$ & $\begin{array}{l}\text { a) Lenta e com todas as dimensões } \\
\text { (3D, 4D, } \\
\text { 5D...) implementadas gradualmente; } \\
\text { b) Rápidas e com todas as dimensões } \\
\text { implantadas juntas; } \\
\text { c) Outros }\end{array}$ \\
\hline $\begin{array}{l}\text { 2) Usando o BIM, você percebeu alguma } \\
\text { melhora no cronograma do seu projeto? }\end{array}$ & $\begin{array}{l}\text { a) } \operatorname{Sim} \\
\text { b) Não }\end{array}$ \\
\hline $\begin{array}{l}\text { 3) Explique, em poucas palavras, como se } \\
\text { deu essa melhoria ou não no cronograma } \\
\text { depois da implementação do BIM. }\end{array}$ & \\
\hline $\begin{array}{l}\text { 4) O escritório possui mão de obra } \\
\text { especializada em BIM? }\end{array}$ & $\begin{array}{l}\text { a) Sim } \\
\text { b) Não } \\
\text { c) Em processo de especialização. }\end{array}$ \\
\hline $\begin{array}{l}\text { 5) Quais softwares BIM são usados no } \\
\text { escritório? }\end{array}$ & \\
\hline $\begin{array}{l}\text { 6) Vocês usam as ferramentas oferecidas } \\
\text { pelo BIM para ter um empreendimento } \\
\text { mais sustentável? (Pergunta voltada para a } \\
\text { dimensão 6D do BIM) }\end{array}$ & $\begin{array}{l}\text { a) Sim } \\
\text { b) Não } \\
\text { c) Outros }\end{array}$ \\
\hline
\end{tabular}

Fonte - Os autores

No caso de a empresa NÃO utilizar o BIM, as perguntas são mostradas da tabela 2:

Tabela 2 - Questionário às empresas que NÃO utilizam a metodologia BIM

\begin{tabular}{|l|l|}
\hline \multicolumn{1}{|c|}{ PERGUNTAS } & \multicolumn{1}{c|}{ ALTERNATIVAS } \\
\hline & a) Sim \\
1) Vocês já pensaram em adotar a & b) Não \\
metodologia BIM para a empresa? & c) Outro \\
\hline
\end{tabular}


Tabela 2 - Questionário às empresas que NÃO utilizam a metodologia BIM

\begin{tabular}{|l|l|}
\hline \multicolumn{1}{|l|}{$\begin{array}{l}\text { 2) Qual a maior dificuldade que avaliam em } \\
\text { adotar a metodologia BIM? }\end{array}$} & $\begin{array}{l}\text { a) Mão de obra especializada } \\
\text { b) Dificuldade de aderir a softwares que } \\
\text { utilizam na metodologia }\end{array}$ \\
\hline $\begin{array}{l}\text { 3) Apresentaram, em algum momento, } \\
\text { problemas ou desvantagem de mercado por } \\
\text { não utilizarem a sistema BIM? }\end{array}$ & $\begin{array}{l}\text { a) Sim } \\
\text { b) Não } \\
\text { c) Outros }\end{array}$ \\
\hline
\end{tabular}

Fonte - Os autores

\section{RESULTADOS E DISCUSSÕES}

O questionário começava com uma pergunta sobre o escritório utilizar ou não BIM nas suas obras. Dependendo da sua resposta, se seria sim ou não, o usuário seria levado a uma sequência de outras perguntas relacionadas às melhorias observadas com o uso do BIM ou os motivos de não estar utilizando essa nova forma de construir. Das 21 respostas obtidas com a pesquisa, $13(62 \%)$ escritórios responderam que utilizavam a metodologia BIM, e $8(38 \%)$ responderam que não utilizavam, como mostra a figura abaixo em porcentagem.

Gráfico 1 - Escritórios que utilizam a metodologia BIM

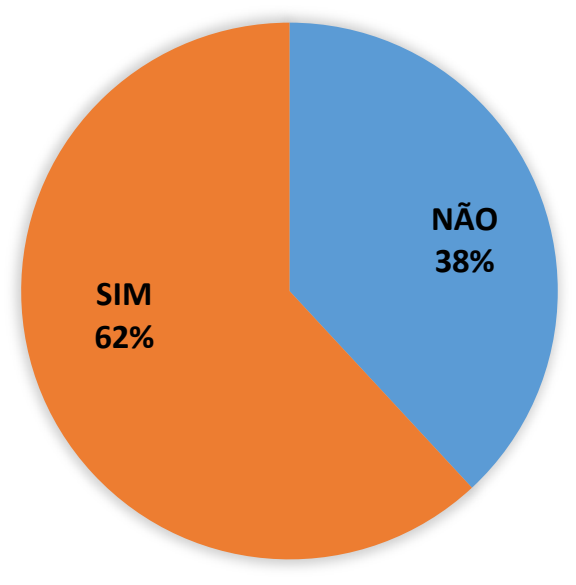

Fonte - Os autores

Os treze escritórios que responderam sim, foram levados a uma sequência de 6 perguntas relacionadas às melhorias que foram observadas com a utilização do BIM. Através das respostas, foi observado que os escritórios concordavam, em sua totalidade, em muitos aspectos, como a melhora no cronograma dos projetos e obras, maior rapidez na entrega de projetos compatibilizados, a diminuição considerável de erros ao longo de todo processo, redução de gastos e satisfação dos clientes no acompanhamento. Apesar de já se utilizar o BIM, em uma das perguntas, 6 (46\%) escritórios responderam que possuem mão de obra especializada, e os outros 7 (54\%), responderam que a mão de obra está em processo de especialização, como mostra a figura abaixo. 
Gráfico 2 - Quanto a mão de obra especializada

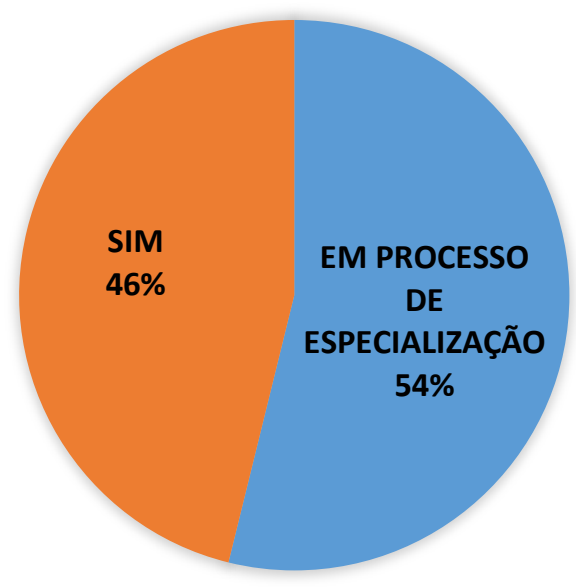

Fonte - Os autores

Em relação à sustentabilidade (6D), fator muito importante dentro da metodologia BIM, foi perguntado aos escritórios, quais deles se utilizavam dessa metodologia para tornar suas obras mais sustentáveis, através das ferramentas avançadas dispostas pelos softwares usados na elaboração dos projetos. Das treze respostas, 7 (54\%) responderam que não se utilizavam dessas ferramentas para tornar a obra mais sustentável, e as outras $6(46 \%)$, afirmaram que se utilizavam das ferramentas. Essa proporção pode ser vista na figura a seguir:

Gráfico 3- Quanto a mão de obra especializada

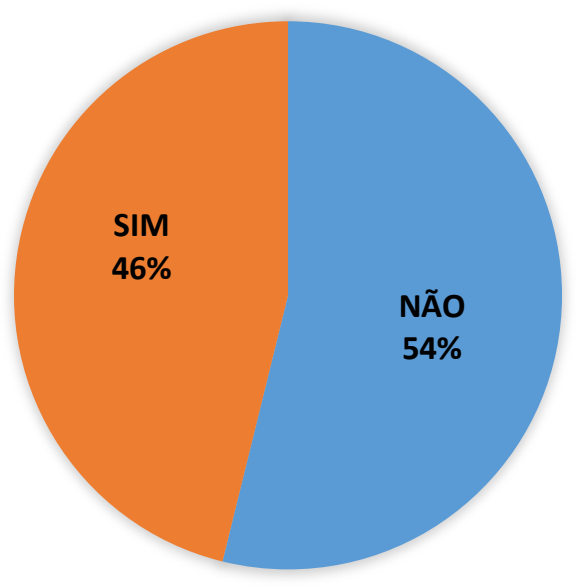

Fonte - Os autores

Os escritórios que responderam, na primeira pergunta do questionário, que não utilizavam BIM, foram levados a uma sequência de perguntas relacionadas aos motivos da não utilização e os possíveis problemas enfrentados no mercado. Como mostra na figura 4, na primeira pergunta dessa sequência, dos oito escritórios que não faziam o uso do BIM, 5 (63\%) responderam que já pensaram em fazer o uso da metodologia BIM, e os outros 3 (37\%), responderam que nunca pensaram. 
Gráfico 4- Quanto a adoção do BIM no escritório.

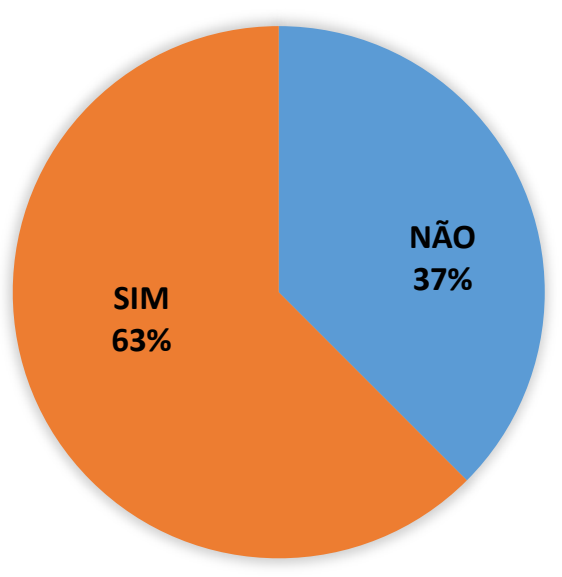

Fonte - Os autores

Quando perguntado em relação à dificuldade de implementar a metodologia BIM, alguns escritórios responderam que a maior dificuldade foi a falta de mão de obra qualificada, e os outros, responderam que a dificuldade principal foi aderir aos softwares que utilizam a metodologia BIM.

A última pergunta foi em relação a algum problema ou desvantagem que perceberam por não fazer uso do BIM no mercado. Como respostas, 5 (71\%) escritórios responderam que não observaram problemas ou desvantagens no mercado, e os outros $2(29 \%)$, responderam que apresentaram essas características, como mostra a figura abaixo.

Gráfico 5 - Quanto a apresentar problemas ou desvantagem de mercado por não utilizar o BIM

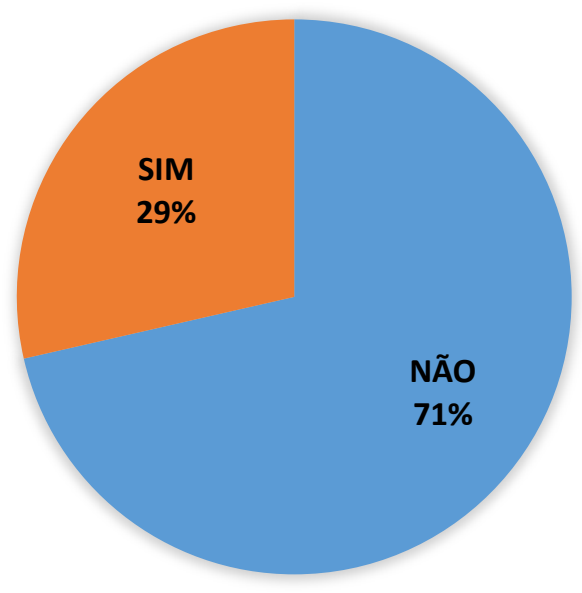

\section{CONCLUSÕES}

Fonte - Os autores

Após a análise dos dados obtidos, é perceptível a evolução dos escritórios de engenharia e arquitetura da região CRAJUBAR em relação ao uso da metodologia BIM, já que a maior 
parte dos escritórios (62\%) já utiliza essa nova forma de construir. As melhorias relatadas pelos escritórios confirmam que o uso do BIM trouxe muitos pontos positivos para os processos construtivos da região. Outro ponto observado, é a falta de mão de obra qualificada, mesmo para quem já faz uso dessa metodologia, mostrando uma deficiência na criação de profissionais qualificados nessa área. Ainda que o BIM tenha preocupações com a sustentabilidade e forneça muitas ferramentas para facilitar o entendimento dos cuidados que devem ser tomados com o meio ambiente, poucos possuem essas preocupações e se utilizam dessas ferramentas.

Os resultados mostram que mesmo as empresas que ainda não utilizam o BIM, pensam em adotar essa metodologia, pois os pontos positivos são vastos. Alguns problemas ainda complicam essa transição dentro do escritório para adotar essa metodologia, como já dito, devido à falta de profissionais qualificados, e a obtenção dos softwares, pois possuem pacotes caros de licenças para utilização. Em contrapartida, é observado que poucos profissionais obtiveram algum problema ou desvantagem no mercado devido a não utilização do BIM. Isso mostra, que na região CRAJUBAR, o mercado ainda permite os processos construtivos mais tradicionais.

A pesquisa mostra, que na região CRAJUBAR, a tendência é os escritórios adotarem e aperfeiçoarem seus métodos através da metodologia BIM. À medida que as tecnologias avançam, as exigências do mercado se tornam maiores e os profissionais devem estar preparados. Ainda com uma deficiência na qualificação de profissionais nessa área, as empresas estão buscando adotar essa nova estratégia, obtendo melhores resultados em todas as etapas de projetos e construções.

\section{AGRADECIMENTOS}

A Liga Acadêmica de Building Information Modeling (LABIM) por prestar apoio técnico e humano na concepção da pesquisa.

\section{REFERÊNCIAS}

BOURDIEU, Pierre. O campo científico. In: ORTIZ, Renato (org.). Pierre Bourdieu: sociologia. São Paulo: Ática, 1983. p. 122-155.

Câmara dos Deputados. Legislação Informatizada - DECRETO Nº 10.306, DE 2 DE ABRIL DE 2020 - Publicação Original. Disponível em: https://www2.camara.leg.br/legin/fed/decret/2020/decreto10306-2-abril-2020-789938publicacaooriginal-160263-pe.html. Acesso em: 30/07/2020.

EASTMAN, Chuck et al. (2014). Manual de BIM: um guia de modelagem da informação da construção para arquitetos, engenheiros, gerentes, construtores.

Gil, Antonio Carlos. Métodos e técnicas de pesquisa social / Antonio Carlos Gil. - 6. ed. - São Paulo: Atlas, 2008.

INSTITUTO BRASILEIRO DE GEOGRAFIA E ESTATÍSTICA - IBGE. Normas de apresentação tabular. 3. ed. Rio de Janeiro: IBGE, 1993.

RAMOS, L. F.; RUGEL. R. R.; AGUILAR, J. M.; más alla de la tecnologia: BIM como una nueva filosofia. Revista CIVILIZATE, Perú, v. 6, p.49, 2016. 